\title{
Das Ethos der Persönlichkeit
}

\author{
Nicolar Hartmann \\ Universität Göttingen
}

1. Was Persönlichkeit ist, lässt sich erst im Gegensatz zur Person sagen. Denn beides ist nicht dasselbe. Person ist jeder Mensch, darin gleichen sich alle; das Personsein als solches ist darum ein Allgemeines, wie sehr auch die einzelnen Personen verschieden sein mögen. Persönlichkeit dagegen ist nicht jeder Mensch. Persönlichkeit ist das an einem Menschen, was er für sich allein hat, was nicht an anderen wiederkehrt, das Einmalige und Einzige an einer Person.

2. Darin ist schon vorausgesetzt, was Person ist. Aber was ist Person? Sie ist nicht das Subjekt und nicht das Ich. Sie ist auch nicht das Bewusstsein, geschweige denn das Selbstbewusstsein. Sie setzt das erkennende Subjekt wohl voraus, desgleichen das geistige Bewusstsein mit seiner Objektivität und seiner charakteristischen Distanz zu den Dingen der umgebenden Welt; aber sie ist noch etwas mehr: das in die Zukunft schauende, vorsorgende, Zwecke setzende, handelnde und im Handeln sich frei entscheidende Wesen, das zugleich den Sinn für Wert und Unwert, das Wissen um Gut und Böse hat und selbst befähigt ist, gut oder böse zu sein.

3. Damit ist sie zugleich das durch seine Aktivität weltoffene Wesen, das von der umgebenden Welt Impulse empfängt und seinerseits handelnd in sie eingreift, sie umgestaltend und das Geschehen umlenkend. Sie zieht, indem sie Dinge benötigt und verwendet eine Sphäre des ihr Zugehörigen um sich, die als Personsphäre zugleich die ihres Eigentums, ihr unmittelbarer Macht-und Einflussbereich ist. Sie erhebt den Anspruch, in dieser Sphäre respektiert zu werden. Denn sie kann in ihr auch verletzt werden. 
4. Die Person fordert für sich die Anerkennung derer, die sie ihrerseits als Personen (mit einer Personsphäre) anerkennt. Das innere Korrelat dieser Forderung ist ihr ethisches Selbstbewusstsein, ihr Auf-sich-halten, Stolz, Würde und Scham.

5. Auf der gegenseitigen Anerkennung beruht die Menschengemeinschaft. Auf die Person bezieht sich die Aristotelische Definition des Menschen als des "von Natur gemeinschaftbildenden Lebewesens". Das bedeutet, dass ein personales Wesen nicht nur den Drang, sondern auch die Fähigkeit hat, seinen Zusammenschluss mit anderen gleichen Wesen zu organisieren.

6. Es gehört ferner die Fähigkeit dazu, sich selbst in Zucht zu nehmen, sich unter Forderungen oder Gesetze zu stellen, die ihm nicht von Natur gegeben sind und nicht aus seinen Artinstinkten entspringen, die ihm dann aber zu Massstäben des Wertbewusstseins werden. Aus dieser Fähigkeit erst entfalten sich die verschiedenen Stufen der Solidarität und der als solcher empfundenen Mitverantwortung für das Ergehen und Handeln anderer Personen. Solche Stufen sind: die Gleichstellung unter dem Recht, das Vertrauensverhältnis (Treu und Glauben) und die allgemeine Nächstenliebe (Altruismus).

7. Zur Person wird der Mensch nicht einfach aus sich selbst heraus, sondern stets auf Grund eines Kulturzusammenhanges, der als geschichtlicher Geist vorbesteht und sich im Wechsel der Generationen herausgebildet hat. Der Einzelne wächst in diesen Zusammenhang hinein, übernimmt ihn im Heranwachsen und übergibt ihn der nächsten Generation weiter; aber er tut es nicht passiv, sondern im Masse seines Könnens trägt er auch das Seinige zu ihm bei. Die Geistesgebiete, auf denen dieser Umsatz läuft, sind: die Sprache, das Recht, die Sitte, die Moral, das Wissen, der Lebensstil, die Kunst, die Religion, die Technik u. a.

8. Die Einzelperson ist auf allen diesen Gebieten Träger einer lebendigen Tradition. Dass er auf keinem Gebiete das Ganze umfasst, hindert ihn daran nicht. Auf manchen Gebieten bedarf es der besonderen Institution (Lehranstalt) und der besonderen Lehrpersonen zur Weitergabe des kulturellen Gutes. Denn der Geist vererbt sich nicht -wie die physischen und manche seelischen Eigenschaften-, sondern bedarf der aktiven Weitergabe. Die Person tritt damit in den unmittelbaren Dienst der Geistesgeschichte. 
9. Ueber alles das hinaus fällt der Person noch eine grössere Aufgabe zu -durch ihr Berufensein zur Lenkung des Geschichtsprozesses. Gäbe es ein überpersonales Bewusstsein mit eigener Aktionsfähigkeit, so wäre der Mensch als Person von dieser Beanspruchung frei. Aber es gibt kein Ueberbewusstsein oberhalb der Einzelperson. Der geschichtliche Gemeingeist hat keines. Nur der personale Geist ist der Einsicht, der Zwecksetzung und Lenkung mächtig. Gerade er aber reicht für die ungeheure Aufgabe, die ihm hier zufällt, nicht zu. Sein Vorblick und seine Zielsetzung sind an den privaten Bedarf des persönlichen Lebens und dessen enge Perspektive angepasst. Dennoch trägt er die Verantwortung für künftige Geschlechter, welche die Früchte seines Tuns ernten werden. Aus diesem Dilemma kommt der Mensch nicht heraus.

\section{II}

10. Zur Persönlichkeit reicht das alles nicht zu. Schon im Leben, diesseits aller Reflexion, meinen wir etwas den Einzelnen Auszeichnendes, wenn wir sagen, er sei eine Persönlichkeit. Denn Persönlichkeit ist das an einem Menschen, was ihm nicht mit anderen gemeinsam ist. Doch darf man hier dem Sprachgebrauch nicht zu weit nachgeben; oft meint man mit Persönlichkeit nur einen Menschen von grösserer Tatkraft, von starkem suggestivem Einfluss auf andere, ausgeprägtem Charakter, oder auch nur den repräsentativen Vertreter eines Menschentypus.

11. Dieser Sprachgebrauch trifft nicht das Wesen der Sache. Er bleibt im Typenhaften stecken, dringt nicht bis in das Individuelle durch. Auch schwache, stille, unaufdringliche Menschen können Persönlichkeit haben. Auf die Eigenart, das Einmalige, die Einzigkeit und Unersetzlichkeit kommt es an. Persönlichkeit ist das an einem Menschen, was wir lieben oder hassen, wofür wir Sympathie oder Antipathie empfinden-meist ohne dass wir sagen könnten, worin es besteht. Auf sie sind fast alle höheren persönlichen Gefühle gerichtet.

12. Mit Individualismus hat das nichts zu tun. Am wenigsten mit dem ethischen. Die allgemeinen sittlichen Forderungen, die für jedermann ohne Unterschied gelten, werden von dem Anspruch der Besonderheit des Einzelnen gar nicht berührt, geschweige denn geschmälert. 
Sie bleiben in Kraft und bleiben die Grundlage, über der sich menschliche Eigenart als Ethos der Persönlichkeit allererst erheben kann.

13. Die ganze Alternative von Allgemein und Individuell -nicht nur am Menschen, sondern überhaupt und an allem Seienden - ist ein Irrtum der alten Metaphysik. Es gibt in der realen Welt nicht zweierlei Seiendes (individuelles und allgemeines), sondern durchaus nur einerlei. Alles Reale, gleichgültig, ob Ding oder Mensch, Ereignis oder $\mathrm{Zu}$ stand, ist individuell, nur freilich meist mit sehr unbedeutenden Differenzen; aber alle Einzelzüge des Individuellen sind allgemein. Der Einzelfall teilt sie mit unzähligen anderen. Was ihn individuell macht, ist lediglich die Kombination der Züge. Diese kehrt nicht wieder und zwar schon deshalb, weil sie bei ihrer Wiederkehr in einen anderen Realzusammenhang eingeordnet und durch ihn jedenfalls eine verän. derte wäre.

14. Dieses Verhältnis ist der einfache Ausdruck eines ontologischen Gesetzes, das nicht durch menschliche Verkennung aufgehoben werden kann. Man kann es auch so aussprechen : Alles Reale ist einzig; aber in ihm steckt schon die Realität des Allgemeinen; denn diese bedeutet nichts anderes als die Gleichartigkeit der einzelnen Züge. Nur das ideale Sein ist ohne Individualität. Dafür ist es auch ein bloss unvollständiges Sein. Die alte Metaphysik — seit Platonischer Zeithat es als das höhere Sein, als "bessere Welt" der reinen Formen verstehen wollen. Die neue Ontologie hat ihm den Nimbus genommen und seine Seinsweise, trotz aller Überzeitlichkeit als die niedere erwiesen. Gerade das zeitliche, vergängliche, individuelle Sein ist das höhere.

15. An Dingen und niederen Lebewesen erscheint uns das Einzigsein gewichtslos, wir haben kein Interesse daran, und so bleibt es völlig unbemerkt. Am Menschen bekommt es für uns Gewicht, weil es auf Persönlichkeit beruht. Wäre der Mensch für den Menschen nicht etwas Besonderes, so würden wir vermutlich nichts Individuelles in der Welt entdecken können.

16. Durch alle Schichten des Menschenwesens erstreckt sich das persönlich Individuelle. Am Körper ist es direkt sinnlich wahr. nehmbar, in der leib-seelischen Sphäre wirkt es sich als durchsichtiger Ausdruck des Inneren im Äusseren aus; am moralischen Wessen der Person erscheint es als Charakter, in der intimen Beziehung von Mensch zu Mensch als das, was den Einzelnen unverkennbar heraus. 
hebt aus der Vielheit der Personen, was aber doch stets im Grunde unerkennbar und unaussprechbar bleibt.

17. Wesentlich ist hierbei auf allen Stufen das anschaulich-konkrete Hindurchleuchten des an sich unsichtbaren Seelisch-Inneren durch das Äussere, -nicht in dessen Gestalt allein, sondern erst recht in der Dynamik der Bewegung, Haltung, mimischer Reaktion, etc. Die Gegebenheit der Persönlichkeit hängt ganz an diesem "Erscheinungsverhältnis". Denn die sprachliche Mitteilung fasst vom seelisch Individuellen nur Bruchstücke. Die Persönlichkeit bedarf, um sich zu zeigen, einer differenzierteren Form der Offenbarung. Es ist mit ihr wie mit dem geistigen Gehalt eines Kunstwerkes: das Denken und seine Logik sind hier viel zu schwerfällig; gerade im Unwägbaren, nur flüchtig und blitzartig Aufleuchtenden, liegt das Wesentliche, und nur das feinste sinnliche Auffassen vermag das Übersinnliche - gleichsam im Fluge - zu ergreifen.

18. Der grosse Unterschied vom Kunstwerk ist nur der, dass hier das Erscheinende real ist. Es ist die geistige und seelische Realität des Menschen, die hier erscheint. Im Kunstwerk offenbart sich das in der Phantasie Erschaute und vom Künstler in die Objektivation Erhobene, in der äusseren Erscheinung des Menschen die wirklich lebende Persönlichkeit. "Real" ist die letztere im Sinne des neuen ontologischen Realitätsbegriffs, der nicht am Räumlichen und Materiellen hängt, sondern an der Zeitlichkeit, dem Werden und der Individualität.

19. Diese Erscheinungsform ist so durchschlagend und der des begrifflichen Denkens so überlegen, dass auch im sittlichen Leben der Völker die führenden Ideen fast immer nur in der Form der Persönlichkeit konkret werden und Anhang finden. Der Mensch lebt nicht auf abstrakte Normen, Gesetze oder Dogmen hin, sondern auf erschaute Gestalten, persönliche "Vorbilder" hin-einerlei ob sie privater Art sind und nur den Einzelnen vorschweben, oder gemeinsame, geschichtlich bewegende Ideale sind. Dadurch allein ist es möglich, dass auch der Dichter geschichtlich weltbewegend auf ein Volk wirkt, das ihn hört und seine Visionen versteht. Denn auch seine "Gestalten" sind, wenn sie überzeugen, dem Leben abgelauscht, und ihre Erscheinungsform ist dieselbe wie die der lebenden Persönlichkeit. Sie leuchten ein nicht durch das, was sie vertreten, sondern dadurch, wie sie sich im Leben verhalten. 
20. Trotz aller Individualität und Konkretheit liegt aber das Kernstück der Persönlichkeit dort, wo sie sich wieder als blosse Person unter Personen in die G'emeinschaft und ihre geschichtlichen Schicksale eingliedert. Denn damit nimmt sie bewusst die Last einer höheren Verantwortung auf sich. Und erst im Tragen dieser Last und im Erstarken unter ihr zeigt sich ihr wahres Ethos. Am Überpersönlichen muss sich das Allerpersönlichste des Menschen bewähren.

21. Denn mit dem eitlen Selbstbewusstsein des Individuums hat echte menschliche Persönlichkeit nichts zu tun. Ein Leben, das die eigene Person zum alleinigen Selbstzweck, das eigene Wesen zum Gegenstand eines Kultus macht, ist eher noch die Verkennung als die Entfaltung der Persönlichkeit. Die wirkliche Eigenart wächst gerade dort, wo der Mensch seine Ziele weit über sich hinaus setzt und sich an Aufgaben hingibt, die ihn über sich hinausreissen. Alle Selbstbespiegelung wirft ihn moralisch zurück. Das wahre Ethos der Persönlichkeit ist kein Ethos des Sichselbstsuchens oder Sichdurchsetzens, sondern der Selbsthingabe und der Selbstvergessenheit.

\section{III}

22. Die letzten Punkte haben gezeigt, wie die Persönlichkeit nicht auf sich selbst gestellt, sondern stets in grössere Zusammenhänge eingebettet dasteht. Das gilt nicht nur von ihrem Sein, sondern auch von ihrem Ethos und ihrem Wissen um sich. Ihr Geheimnis ist ein kategoriales. Sie ist ein Gebilde sui generis mit eigener Daseinsform. Diese letztere aber ist, wie in der ganzen Welt stets die höhere Form, eine "aufruhende", von anderen Seinsformen getragene und insofern abhängige. Das hindert -entsprechend dem kategorialen Aufhaugesetz in der Schichtung der realen Welt- nicht ihre innere Autonomie.

23. Der Mensch als Person bildet durch seine eigentümliche Erhaltungsform (seine Konsistenz) eine Art sekundärer Substanz, an der die Zustände wechseln. Als solche ist sie das tragende Element der grösseren Personenverbände, und diese Trägerschaft gehört mit zu ihren Aufgaben, aus denen man sie nicht herausreissen kann, ohne ihr den Boden zu entziehen, auf dem sie steht. Etwas Ähnliches gilt aber auch für die individuelle Persönlichkeit, und zwar deswegen, weil es zu ihrem Wesen gehört, das was sie ist auch "für jemand" zu 
sein. Da sie es aber nicht für sich sein kann, so kann sie es nur für andere Personen sein.

24. Die Persönlichkeit ist das eminent weltoffene Innenwesen des Einzelmenschen. Sie ist nicht nur durch ihre Seinsbedingungen, sondern noch weit mehr durch den Sinngehalt ihres Daseins, durch ihr Ethos und ihren Wertgehalt in ihre umgebende Welt, die geistig-kulturelle Menschenwelt, hineinbezogen. Und wie schon das blosse Personsein einen Kreis des Zugehörigen, eine Macht-und Einflusssphäre um sich her zieht, die die Person als die ihrige prägt, so auch die Persönlichkeit. Wir kennen solche persönlich geprägte Sphären im Leben als ihren dinglich-häuslichen Alltagskreis, ihren Wirkungskreis, ihren Freundeskreis (stets mit sehr eigenartig bestimmter Auslese), und wenn es hoch kommt, als ihren durch Ideen bestimmten Jüngerund Anhängerkreis. Ja, in gewissem Sinne kann man auch ihren Gegnerkreis dazu rechnen. Denn auch er ist durch ihr persönliches Ethos bestimmt.

25. Als "sekundäre Substanz" wirkt sich in der realen Welt jede stärkere Konsistenz, d. h. jedes sich irgendwie längere Zeit identisch erhaltende Gebilde aus. Mit Substantialität im strengen Sinne hat das nichts zu tun. So ist es auch mit der Erhaltung der Persönlichkeit. Von einem Hineinspielen "höherer" Seinsordnungen, etwa der eines Überzeitlichen (wie man manchmal geglaubt hat) ist dabei keine Rede. Aber ebenso sehr muss man sich hüten, die personale Identität auf Einheiten anderer Grössenordnung zu übertragen, wie das im metaphysischen Idealismus geschehen ist: es gibt durchaus keine $\ddot{U}$ berperson grösseren Stils, die Menschengemeinschaften bilden keine personalen Einheiten, obgleich sie aus Personen bestehen, -genau so wenig wie sie ein Subjekt oder ein Bewusstsein grösseren Stils ausmachen. Und das gilt von ihnen, obwohl sie geschichtliche Individualität haben.

26. Es ist ein Irrtum, dass die sogenannte Menschenkenntnis des Lebenserfahrenen ohne weiteres den Zugang zur Persönlichkeit habe. Was der Menschenkenner erfasst, sind stets nur einzelne hervorstechende Eigenschaften, Fähigkeiten oder Schwächen. Diese aber verführen zur typisierenden Auffassungsweise. Alles Typenhafte nun ist gerade das Gegenteil von Individualität. Der Menschenkenner registriert die Personen nach gewissen immer wieder begegnenden Grundzügen; über diese hinaus in sie einzudringen hat er keinen 
Anlass. Gerade darauf beruht seine Treffsicherheit; in der unbegrenzten Differenziertheit des eigentlich Persönlichen könnte er mit solcher Vereinfachung sich niemals zurechtfinden. Sein schnell fertiges Urteil ist um den Preis der Persönlichkeit erkauft. Diese kann er bei seiner lebenspraktischen Einstellung gar nicht sehen.

27. Die Persönlichkeit erfasst nur der persönlich interessierte, verweilende, sich liebevoll in sie vertiefende Blick. $\mathrm{Zu}$ solchem Verweilen und solcher Vertiefung bedarf es der Zeit, der Hingabe, des Einsatzes, ja nicht selten auch des Wagnisses-lauter Dinge, die wir im Drang des Lebens nur selten einmal aufbringen. Daher der hohe Wert, den es für die Persönlichkeit hat, wenn sie sich einmal wirklich von einem hingebend verweilenden Blick getroffen, sich verstanden und gewürdigt fühlt. Für sie ist es die Sinnerfüllung, die sie selbst sich nicht geben kann: das Bewusstsein dessen, was sie ist, -im Spiegel der fremden Persönlichkeit.

28. Ethisch gesehen, hat dieses Verhältnis aber noch eine andere Seite. Sichtbar nämlich wird dem liebenden Blick nicht nur die empirische Persönlichkeit als das, was sie durch ihr Leben und ihre Schicksale geworden ist, der empirische "Charakter" mit seinen Schwächen und seinem vielfachen Verfehlen des eigenen Wesens. Hinter alledem wird ihm die ideale Persönlichkeit greifbar, der Mensch, wie er in seiner besonderen Eigenart sein sollte. Denn vieles kann den wirklichen Menschen von seinem eigensten Wesen, seinem individuellen Wert, ablenken. Ein Menschenleben kann seinen intelligiblen Charakter verfehlen oder erfüllen, und in der gewordenen empirischen Persönlichkeit ist stets beides, oft so verhängnisvoll gemischt, dass das Eigentliche in ihr unter dem Uneigentlichen her kaum mehr erkennbar ist. Der liebende Blick aber kann hindurchstossen bis auf das Wesen und den Menschen in dessen Lichte sehen.

29. Dass es einen solchen individuellen Wert im Hintergrunde der Persönlichkeit gibt, ist das grösste Wunder im Wesen der Persönlichkeit. Es macht recht eigentlich erst das individuelle Ethos der Persönlichkeit aus. Worin inhaltlich ein Wert besteht, der nicht gemeinsam, sondern nur einem einzelnen Individuum eigen ist, lässt sich schwer sagen. Aber dass er besteht, und zwar unabhängig vom Grade seiner Verwirklichung in der realen Person, lässt sich nicht bestreiten. Denn gerade in der Fühlung mit ihm besteht die persönliche Liebe, filie dem Menschen gilt. Der Liebende eben sieht nicht, was 
vor Augen ist, -da ist er manchmal wohl blind-, sondern was dahintersteht, auch wenn es sich nicht zur Wirklichkeit hat durchringen können. In diesem Sinne ist er der allein Sehende.

30. Ein direktes Erstreben des individuellen Persönlichkeitswertes ist nicht möglich; das würde einen bewussten Kultus der eigenen Person ergeben, und es ist wohlbekannt, wie leicht ein solcher in eitles Selbstbewusstsein umschlägt und so zur gröblichen Selbstverfehlung wird. Wohl aber gibt es ein Hingelenktwerden der Person auf ihn durch den liebenden Blick einer anderen Person. Diese sieht den idealen Persönlichkeitswert als den des Anderen, und darum ohne die Gefahr der Verfälschung. Sie braucht ihn auch dem Geliebten nicht bewusst zu machen, sie lenkt ihn einfach durch die Kraft ihrer Liebe auf ihn hin. Denn diese geheimnisvolle Macht hat die persönliche Liebe, dass sie ihren Gegenstand zu dem wandelt, was sie in ihm liebt.

31. Es unterliegt keinem Zweifel und ist nie bestritten worden, dass in dem Widerspiel von Lieben und Geliebtsein eine einzigartige Sinngebung des Menschenlebens liegt. Aber man hat sich selten einmal klar gemacht, worin sie besteht. Am Ethos der Persönlichkeit wird die Sinngebung verständlich. Denn in ihm liegt der komplementäre Wert zum sittlichen Wert persönlicher Liebe. Schon Platon wusste, dass alle Liebe auf einen Wert gerichtet ist, den sie selbst nicht hat. In der persönlichen Liebe aber ist dieser Wert das ideale Wesen der Persönlichkeit. Und indem sie den Menschen durch ihre bewegende Kraft auf dieses sein Wesen hinlenkt, bringt sie ihn mittelbar zur Selbstverwirklichung der Persönlichkeit.

[TRADUCCIÓN]

El "ethos" de la personalidad

Nicolai Hartmann

Universidad de Gotinga

I

1. Lo que es la personalidad puede decirse sólo en contraposición a la pérsona. Pues ambas cosas no son lo mismo. Todo hombre es yersona: en 
esto todos son semejantes; el ser persona, en cuanto tal, es, por tanto, algo general, por más que las personas individuales difieran entre sí. En cambio, no todo hombre es persox́alidad. Personalidad es todo aquello del hombre que él solo posee, lo que no se repite en otros, lo que de una persona es irrepetible $y$ único.

2. En todo esto se supone ya la noción de persona. Pero ¿qué es la persona? No es el sujeto ni el yo. Tampoco es la conciencia ni mucho menos la autoconciencia. Ciertamente, supone al sujeto cognoscente e igualmente a la conciencia espiritual con $8 u$ objetividad y $8 u$ distancia caracteristica frente a las cosas del moundo en torno; pero es aún algo más: es el ser que mira hacia el futuro, el ser previsor que pone fines, el ser actuante que al actuar decide libremente, y que, al mismo tiempo, posee el sentido para el valor y el desvalor, el saber del bien y del mal, siendo él mismo susceptible de ser bueno o malo.

3. La persona es, asimismo, el ser abierto al mundo en virtud de su actividad; el ser que recibe impulsos del mundo circundante y que, a su vez, influye sobre él con la acción, transformándolo y modificando el curso de Ios acontecimientos. Al necesitar y utilizar las cosas, traza alrededor de ellas una esfera de pertenencia, la que, en cuànto esfera personal, es al mismo tiempo, la de su patrimonio, la del ámbito de su inmediato poderio e in. fluencia. Reclama ser respetada en esta esfera, pues en ella puede ser también vulnerada.

4. La persona exige para si misma el reconocimiento de aquellos a quie. nes a su vez reconoce como personas (juntamente con una esfera personal). El correlato interno de esta exigencia es su autoconciencia ética, la propia estima, la gallardía, la dignidad y el pudor.

5. En el reconocimiento reciproco se basa la comunidad de los hombres. A la persona se refiere la definición aristotélica del hombre, en cuanto "ser viviente que, por su naturaleza, forma comunidad". Esto significa que un ser personal no solamente posee el impulso, sino también la capacidad de or. ganizar su unión con otros seres semejantes.

6. A ello corresponde, además, la capacidad de la autoeducación, del autosometimiento bajo exigencias y leyes que, a pesar de no estar dadas naturalmente ni originadas en los instintos de su especie, llegan a convertirse para ella en medidas de su conciencia axiológica. Sólo en virtud de esta capacidad se van desplegando los distintos grados de la solidaridad y de la responsabilidad común, sentida como tal para el porvenir y la actuación de otras personas. Tales grados son: la posición igualitaria ante el derecho, la relación de confianza (la buena fe) y el amor universal al prójimo (altruismo).

7. El hombre se hace persona no simplemente partiendo de sí mismo, sino que siempre necesita basarse en una conexión de cultura, previamente existente en cuanto espiritu histórico y desarrollado a través del cambio de Jas generaciones. El individuo singular se incorpora paulatinamente a esta conexión, la recoge al madurar y la transmite a la próxima generación; pero esto no lo:nace pasivamente, sino que, en la medida de sus facultades, con. 
tribuye a ello con su propio aporte. Los dominios del espirita en que tal transformación se produce, son: el lenguaje, el derecho, la costumbre, la moral, el eaber, el estilo de vida, el arte, la religión, la técnica, etc.

8. La persona singular figura, en todos esos terrenos, como portadora de una tradición viviente, y no es obstáculo para esto que ninguno de ellos abarque la totalidad. En algunos terrenos la transmisión del bien cultural requiere una institución particular (la institución educacional) y educadores especiales, pues el espíritu no se transmite por herencia - como las propiedades físicas y algunas anímicas-, sino que necesita de una transmisión activa. Con ello la persona entra en el servicio inmediato de la historia del espiritu.

9. Además de todo esto, le compete a la persona una misión más grande aún: está llamada a dirigir el proceso de la historia. Si existiese una conciencia suprapersonal dotada de propia capacidad de acción, el hombre, en cuanto persona, estaria liberado de esta carga. Pero no existe ninguna supraconciencia por encima de la persona singular. El espiritu común histórico no posee conciencia. Solamente el espiritu personal tiene cl poder de la intelección, de proponerse fines y de conducción. Pero, precisamente, no es adecuado para la tarea ingente que le es impuesta. Su providencia y establecimiento de fines se amoldan a los menesteres particulares de $8 \mathrm{u}$ vida privada y a su estrecha perspectiva. Sin embargo, pesa sobre èl la responsabilidad para con las generaciones futuras que cosecharán los fratos de su hacer. El hombre no puede escapar a este dilema.

\section{II}

10. Todo esto no es suficiente para constituir la personalidad. Ya cn la vida, antes de toda reflexión, aludimos a una nota distintiva del individuo, cuando decimos que es una personalidad. En efecto, la personalidad es aquel rasgo del hombre que no le es común con otros. Mas a este respecto no hay que hacer demasiadas concesiones a la terminologia corriente; a menudo la expresión personalidad se refiere solamente a un hombre cos mayor energia, con una fuerte influencia sugestiva, un carácter marcado, y a veces solamente a un individuo representativo de un tipo de hombre.

11. Esta terminología usual no da en la esencia de la cuestión. Se queda en la tipicidad, sin penetrar hasta lo individual. También hombres débiles, callados, no llamativos, pueden tener personalidad. Lo decisivo es la peculiaridad, lo irrepetible, lo único, lo irreemplazable. Pcrsonalidad es aquella condición de un hombre que amamos u odiamos, por el cual sentimos sim. patia o antipatía - frecuentemente, sin que podamos decir en qué consiste. Hacia ella convergen casi todos los sentimientos personales superiores.

12. Esto no tiene nada que ver con el individualismo, ni mucho menos con el individualismo ético. Las exigencias éticas generales, válidas para todos sin distinción alguna, no son afectadas ni menos aún restringidas por la pretensión de peculiaridad propia del individuo. Quedan bp vigor, y 
siguen formando la base sobre la cual se puede levantar la peculiaridad humana, en cuanto "ethos" de la personalidad.

13. La alternativa universal-individual - no solamente la que concierne al hombre, sino la gencral que se refiere a todo ente- es un error de la vieja metafísica. En el mundo real no existen dos clases de entes (el ente individual y el ente universal), sino nada más que una. Todo lo real, ya sea una cosa o un hombre, ya sea un acontecimiento o estado, es individual, aunque frecuentemente sólo con diferencias muy pequeñas; pcro todos los rasgos singulares de lo individual son universales. El caso individual to comparte con un sinnúmero de otros. Lo que constituye su individualidad es meramente la comb́inación de los rasgos. Ella no puede repetirse, por la sola razón de que al retornar estaria inserta en otra conexión real distinta y por la sola virtud de ella se transformaria.

14. Esta interrelación es la simple expresión de una ley ontológica que ninguna ignorancia humana puede desvirtuar. Se puede formular también de la siguiente manera: todo lo real es único, pero en èl habita ya la realidad de lo universal; pues ésta no significa otra cosa que la homogeneidad de los rasgos individuales. Sólo el ser ideal carece de individualidad. Por ello es también meramente un ser incompleto. La vieja metafísica, desde la época platónica en adelante, quería comprenderlo como el ser superior, como el "mundo mejor" de las formas puras. La nueva ontología lo privó de este nimbo, demostrando que su manera de ser, pese a toda atemporalidad, es la inferior. Precisamente el ser temporal, perecedero e individual, es el superior.

15. El ser individual de las cosas y entes vivientes inferiores nos parece falto de peso, nci tenemos ningún interés en él, de modo que permanece completamente inadvertido. En el hombre adquiere importancia para nosotros, porque se debe a la personalidad. Si el hombre no fuera algo particular para el hombre, es de suponer que no podriamos descubrir en el mundo nada que taviera individualidad.

16. Lo individual personal se extiende a través de todos los estratos del ente humano. En el cuerpo se deja percibir directamente por medio de los sentidoł; en la esfera corpóreo-animica se plasma en lo exterior como expresión diáfana de lo interior; en el ente moral, la persona se manifiesta como carácter, y en la relación intima entre hombre y hombre, como aquello que destaca al individuo inequívocamente frente a la multiplicidad de las personas, pese a que, en el fondo, permanece inescudriñable e inefable.

17. Lo esencial de todos esos grados consiste en que lo animico interior, en sí invisible, se hace intuitiva y concretamente traslúcido por medio de lo externo, y no sólo en la configuración propia de este último, sino mas bien $y$ precisamente en la dinámica del movimiento, del hábito externo, de la reacción mímica, etc. El darse de la personalidad radica enteramente en esta "relación fenoménica", puesto que la comunicación idiomática aprehende solamente trozos fragmentarios de lo individual anímico. Para mostrarse, la personalidad necesita una forma más diferenciada de manifes- 
tación. Ocurre con ella lo que con el contenido espiritual de una obra de arte: el pensar y su lógica son demasiado torpes; su esencia reside precisa-

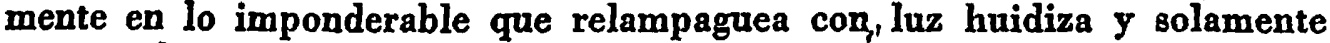
una aprehensión sensible más afinada es capaz de captar lo suprasensible, casi diriamos al vuelo.

18. La gran diferencia frente a la obra de arte consiste en que lo que se manifiesta aqui, es real. Lo que se fenomenaliza en este caso es la realidad espiritual y animica del hombre. En la obra de arte se patentiza lo que el artista ha intuído en la fantasía y elevado a la objetivación; en la aparición exterior del hombre se ostenta la viviente personalidad real. "Real" es esta uiltima, en el sentido del nuevo concepto ontológico de realidad que, en lugar de referirse a lo espacial y material, se funda en la temporalidad, en el devenir y la individualidad.

19. Esta forma fenoménica tiene una contundencia tal y es tan superior al pensar conceptual, que las ideas directrices hasta en la vida moral de los pueblos se concretan y encuentran prosélitos casi siempre tan sólo en forma de personalidad. El hombre no se orienta en su vida por normas, leyes, - dogmas abstractos, sino por figuras intuídas, por "modelos" personales, ya sean de indole privada, válidos sólo para un individuo singular, ya sean ideales comunes que conmueven la historia. Sólo de tal manera es posible que también el poeta tenga una influencia histórica que impulse al mundo de un pueblo, porque lo escucha y comprende sus visiones. En efecto, si las figuras del poeta convencen, es porque han sido extraidas de la vida, y su forma fenoménica es igual a la de la viva personalidad: son evidentes no por aquello que representan sino por la manera de conducirse en la vida.

20. El punto medular de la personalidad reside, pesci a toda individua. lidad y concreción, allí donde ella vuelve a incorporarse como mera persona, entre otras, a la comunidad y ous destinos históricos. Con ello, en efecto, asume conscientemente la carga de una responsabilidad superior. $Y$ sólo soportándola y fortaleciéndose bajo su peso, se manifiesta su verdadero "ethos". En lo suprapersonal tiene que probarse lo más personal del hombre.

21. La personalidad humana auténtica no tiene nada que ver con la vana autoconciencia del individuo. Una vida que hace de la pripia persona su finalidad exclusiva y última, y de la propia esencia objeto de culto, equivale más al desconocimiento que al despliegue de la personalidad. La verdadera idiosincrasia brota precisamente cuando el hombre sitúa sus fines muy lejos de sí y se entrega a tareas que lo arrancan de su propia esfera. Todo autoespejismo es una recaída moral. El "ethos" verdadero de la personalidad no consiste en el "ethos" de una búsqueda de sí mismo o de un hacerse valer, sino en la entrega y olvido propios.

\section{III}

22. En los últimos puntos se ha mostrado que la personalidad no está remitida sólo a sí misma, sino que se encuentra siempre encauß̧ada en co- 
nexiones más amplias. Esto vale no solamente para su ser, sino también para su "ethos" y su saber de sí. Su secreto es categorial. Ella es una entidad sui generis con una forma propia de existencia. Pero por ser la última, como siempre ocurre con las formas superiores en el mundo entero, tiene que "apoyarse" sobre formas de eer portadoras, y es a este respecto dependiente. Esto no obsta a su autonomía intrinseca, conforme a la ley de la construcción categorial que rige en la estratificación del mundo real.

23. El hombre como persona constituye, por su peculiar forma de conservación (su consistencia), una suerte de substancia secundaria cuyos estados cambian. En cuanto tal, clla es el elemento portador de uniones de personas más amplias, y esta función portadora pertenece a sus tareas, de las cuales no se la puede arrancar sin sacarle el suelo en que está colocada. Algo semejante vale también para la personalidad individual, porque pertenece a su esencia el ser también "para alguien" lo que es. Pero, dado que para ella misma no lo puede ser, lo podrá ser tan sólo para otras personas.

24. La personalidad es la esencia intima del hombre individual abierta por antonomasia al mundo. No solamente en virtud de las condiciones de su ser, sino más aún por el contenido significativo de su existencia, el "ethos" y el contenido de valor suyos, ella se encuentra incorporada a su mundo circundante, al mundo espiritual-corporal del hombre. $Y$ como ya el ser de la mera persona traza alrededor de si un círculo de pertenencia, una esfera de poder de influencia que llevan el sello de propiedad de la persona, así también lo hace la personalidad. Conocemos en la vida tales esferas do cuño personal como el círculo cotidiano de las cosas caseras, el círculo de su actividad, el círculo de amistades (caracterizado siempre por una selección peculiarmente determinada), y a lo sumo como el círculo de sus discípulos y adeptos definidos por ideas. En cierto sentido podría agregarse también hasta el círculo de sus enemigos; ya que también éste radica en su "ethos" personal.

25. Como "sustancia secundaria" se hace valer en el mundo real cualquiera consistencia más firme, es decir, cada entidad que de algún modo se conserva como idéntica por un tiempo mayor. Esto no tiene nada que ver con la sustancialidad en sentido estricto. Así ocurre también en el caso de la conservación de la personalidad. El interferir de órdenes de ser "superiores", por ejemplo, de su orden supra-temporal, según a veces se ha supuesto, no viene aquí a cuento en modo alguno.

Por otra parte hay que guardarse de trasponer la identidad personal a unidades pertenecientes a órdenes de distinta amplitud, tal como ocurrió en el idealismo metafísico: la suprapersona de índole más amplia no existe en absoluto, las comunidades humanas no forman en ningún caso unidades personales aunque se componen de personas, como tampoco constituyen un sujeto o una conciencia de indole más amplia. Y esto vale para ellas a pesar de que tengan individualidad histórica.

26. Es un error creer que el llamado conocimiento de hombres, propio del experimentado en la vida, tiene sin más ni más acceso a la personalidad. Lo que tal conocedor de hombres capta es solamente propiedades, capaci- 
dades o debilidades singulares destacadas. Pero éstas inducen a caer en una manera de aprehensión tipificante. Ahora bien, todo lo típico es precisamente contrario a la individualidad. El conocedor de hombres registra a las personas según ciertos rasgos fundamentales que se repiten continuamente; no tiene ningún motivo para penetrar en ellas más allá de estos rasgos. Precisamente en ello radica su certeza de dar en el blanco. Nunca podría orientarse mediante tal simplificación en el ámbito ilimitadamente diferenciado de la personalidad propiamente dicha. Su juicio rápidamente formado se adquiere al precio de la personalidad. $Y$ ésta ni siquiera es perceptible en su actividad vital-práctica.

27. La personalidad no es aprehensible sino para la mirada personalmente interesada, que penetra sosegada y cariñosamente en ella. Para tal morar sosegado y para tal ahondamiento se necesita tiempo, entrega, sacrificio y no raras veces hasta riesgo, actitudes que, en el apresurado curso de la vida, pocas veces alcanzamos. De aquí el alto valor que tiene para la personalidad el sentirse una vez realmente alcanzada, comprendida y valorada por una mirada toda sosiego y entrega. Para ella, esto significa el cumplimiento de sentido que ella misma no puede procurarse, es decir la conciencia de lo que ella es, en el espejo de la personalidad ajena.

28. Esta correlación tiene un aspecto distinto desde un punto de vista ético. En efecto, la mirada amorosa capta la personalidad empírica no sólo como lo que clla por su vida y su destino ha llegado a ser, es decir, el "carácter" empírico con sus debilidades que muchas veces yerra la propia esencia; detrás de todo ello se le hace palpable la personalidad ideal, el hombre como, gracias a su idiosincrasia particular, debiera ser. Pues hay muchas cosas que pueden desviar al hombre real de su esencia más propia, de su valor individual. Una vida humana puede errar su carácter inteligible o cumplirlo; ambas actitudes se hallan siempre entremezcladas en la personalidad empirica desarrollada, y a menudo de una manera tan funesta que lo propio de ella es apenas perceptible bajo lo impropio. La mirada cariñosa empero puede penetrar a través de ella hasta la esencia y avistar al hombre a la luz de ésta.

29. El que exista ese valor individual en el transfondo de la personalidad es la maravilla más grande de la esencia de la personalidad. Ella constituye el "ethos" individual de la personalidad propiamente dicha. Es dificil decir qué es el contenido de un valor no común, sino propio tan sólo de un individuo único. Pero es incontestable que existe y con independencia del grado de su realización en la persona real. Pues precisamente en el contacto íntimo con este valor consiste el amor personal sentido hacia el hombre. Precisamente el que ama no ve lo que está a la vista - para ello estará ciego en ocasiones-, sino lo que se halla tras ello, aunque no haya podido abrirse camino hasta la realidad. En este sentido el que ama es el único vidente.

30. Un tender hacia el valor de la personalidad individual no es posible; de ello resultaría un consciente culto de la propia persona y es demasiado sabido que tal actitud se transforma fácilmente en una vana autoconciencia, llegando luego a una grosera equivocación sobre si mismo. Pero sí existe 
una manera de orientar a la persona por la mirada amorosa de otro. Esta percibe el valor ideal de la personalidad como la del otro, y por ello mismo sin el peligro de ultrajarla. No es necesario que ella haga consciente il amado este valor, sino que por medio de la fuerza de su amor lo conduce simplemente hacia él. En efecto, el amor personal tiene cstc poder enigmático de transformar su objeto en aquello que él ama.

31. No hay ninguna duda ni ha sido nunca discutido que en la interrelación existente entre el amar y el ser amado hay una prestación de scntido peculiar de la vida humana. Pero raras veces ha sido esclarccido en qué consiste. La prestación de sentido se hace comprensible en el "ethos" de la personalidad. Pues en él reside el valor complementario del valor ético propio del amor personal. Ya Platún supo que todo amor está dirigido hacia un valor que él mismo no posee. Pero en el amor personal este valor equivale a la esencia ideal de la personalidad. $Y$ al conducir al hombre por su fuerza motriz hacia este su ecr, le hace alcanzar mediatamentc la autorealización de la personalidad. 